\title{
COMPARATIVE AMS RADIOCARBON DATING OF PRETREATED VERSUS NON-PRETREATED TROPICAL WOOD SAMPLES
}

\author{
Adrian Patrut ${ }^{{ }^{*}}$, Karl F. von Reden ${ }^{2 *}$, Daniel A. Lowy ${ }^{3}$, Diana H. Mayne ${ }^{4}$, \\ Kathryn E. Elder ${ }^{2}$, Mark L. Roberts ${ }^{2}$, Ann P. McNichol ${ }^{2}$ \\ ${ }^{1}$ Department of Chemistry, Babes-Bolyai University, 400028 Cluj-Napoca, Romania \\ ${ }^{2}$ NOSAMS Facility, Department of Geology \& Geophysics, Woods Hole \\ Oceanographic Institution, Woods Hole, MA 02543, U.S.A. \\ ${ }^{3}$ Nova Research Inc., Alexandria, VA 22308, U.S.A. \\ ${ }^{4}$ Baobab Trust, PO Box 1566, Parklands 2121, Johannesburg, South Africa \\ *Corresponding authors: \\ A. Patrut, apatrut@gmail.com; +40-722-214633; Fax: +40-264-590818. \\ K.F. von Reden, kvonreden@,whoi.edu; +1-508-289-3384; Fax: +1-508-457-2183.
}

\begin{abstract}
Several wood samples collected from Dorslandboom, a large African baobab (Adansonia digitata L.) from Namibia, were investigated by AMS radiocarbon dating subsequent to pretreatment and, alternatively, without pretreatment. The comparative statistical evaluation of results showed that there were no significant differences between fraction modern values and radiocarbon dates of the samples analyzed after pretreatment and without pretreatment, respectively. The radiocarbon date of the oldest sample was $993 \pm 20$ BP. Dating results also revealed that Dorslandboom is a multi-generation tree, with several stems showing different ages.

PACS: 93.30.Vs; 93.30.Bz; 06.60.Ei
\end{abstract}


Keywords: $\mathrm{AMS}{ }^{14} \mathrm{C}$ dating, tropical trees, Adansonia digitata, gas ion source, pretreatment

\section{Introduction}

After over one hundred years of research, determining the ages and growth rates of tropical trees is still a challenging topic [1]. If trees exhibit annual/seasonal growth rings, ring counting is the most accurate and reproducible method for age and growth rate determination. However, the existence of annual/seasonal rings in tropical trees is very controversial [1-5]. Consequently, for tropical trees with growth rings that are not strictly annual or seasonal, without well defined rings and/or a continuous sequence of rings, due especially to hollow parts, radiocarbon analysis represents the only accurate method for dating $[5,6]$. According to the usual procedure, wood samples are pretreated prior to radiocarbon dating. Pretreatment is considered necessary to remove non-structural mobile carbon, primarily lignin, in order to isolate for dating exclusively the structural non-mobile carbon components, mainly cellulose [7].

One of the latest AMS developments is the continuous-flow AMS (CFAMS) which uses a genuine gas ion source, allowing for instantaneous analysis of minute amounts of sample [8, 9]. Long wood samples can be investigated point-by-point by CFAMS, providing a continuous stream of information on age values and growth rate variations of the whole length of the investigated samples. Unlike standard AMS and other techniques in which wood samples are pretreated prior to dating, CFAMS has the capability of analyzing wood samples instantaneously with a very high accuracy, if pretreatment is not necessary.

The main aim of the research was to establish whether pretreatment is mandatory or not for the accurate radiocarbon dating of wood samples collected from tropical tree species with low non-structural mobile carbon content. As the model species we chose the African baobab (Adansonia digitata L.). Species of the genus Adansonia, which belongs to the Malvaceae family, are tropical trees whose woody tissue (xylem) contains little nonstructural carbon, mainly lignin [10]. 
Several wood samples collected from Dorslandboom, a large African baobab, were investigated by AMS radiocarbon dating, with and without pretreatment. Other objectives of our study were to determine its age and the history of its multi-stemmed trunk.

\section{Materials and methods}

Dorslandboom and its area. "Die Dorslandboom" (The Thirstland tree, in Afrikaans), also called "sewe stam kremetart" (seven-stemmed baobab, in Afrikaans), is located in Eastern Bushmanland, Namibia. Its GPS coordinates are: $19^{\circ} 18.047^{\prime} \mathrm{S}, 020^{\circ} 39.640^{\prime} \mathrm{E}$ and the altitude is $1128 \mathrm{~m}$. Mean annual rainfall and temperature in the area are: $451 \mathrm{~mm}$ and 21.5 ${ }^{\circ} \mathrm{C}$. With its toppled or standing knitted stems, some of them broken and a few regenerated with new shoots, Dorslandboom (Fig. 1) can be considered a kind of "Schrödinger's baobab", which is at the same time dead and alive [11]. The largest stem (A) collapsed and died in 2006 and is severely decayed. Two stems ( $F$ and G) collapsed before 1880 but their remains are still alive, one leaning stem (E) is alive, while three stems (B, C and D) toppled but new shoots grew at the ends of broken stems. The largest stem A consisted practically of two fused stems (A1 and A2), so that Dorslandboom could be described more accurately as an eight-stemmed baobab. Its structure was completed recently by two very young stems (X and Y), which sprouted from roots. Measurements indicated a restored circumference at breast height (cbh, i.e., at $1.30 \mathrm{~m}$ above ground) of $36.30 \mathrm{~m}$, which also includes several empty spaces between stems and a maximum height of $14.0 \mathrm{~m}$.

Several large wood samples were collected from the deep scooped-out holes in the bases of three stems of Dorslandboom (A1, B, E). Six smaller samples were extracted from determined positions of the larger samples and marked 1 to 6 . Each smaller sample was further divided in two parts, which were radiocarbon dated by AMS. The part of each sample which was analyzed subsequent to pretreatment was labeled by $a$, while the part analyzed without pretreatment was noticed by $b$. 
Sample preparation. For samples $1 a-6 a$, the acid-base-acid pretreatment method [12] was used to remove soluble and mobile organic components prior to AMS investigation. The wood samples $1 b-6 b$ were investigated by AMS without pretreatment.

AMS measurements. Radiocarbon measurements were performed at the NOSAMS Facility of the Woods Hole Oceanographic Institution with a 3 MV Tandetron (TM) AMS system. Calibration. Fraction modern values were converted to calendar (cal) ages with the OxCal v4.0.3 for Windows [13], by using the IntCal04 atmospheric data set [14].

Statistical analysis. The comparative analysis of AMS dating results acquired by the two methods, i.e., with and without pretreatment, was performed by using the paired $t$-test and the Statistica 7.0 software $[15,16]$.

\section{Results and Discussion}

Fraction modern values and radiocarbon dates. Fraction modern (Fm) values and radiocarbon dates of samples are listed in Table 1. Radiocarbon dates and errors were rounded to the nearest year. The comparative $F m$ values and radiocarbon dates for the samples analyzed via two different methods, i.e., with pretreatment (samples $1 a-6 a$ ) and without pretreatment (samples $1 b-6 b$ ), show small differences, which are within the experimental errors. Also, no significant differences between Fm values and radiocarbon dates of pretreated vs. non-pretreated wood samples are evidenced by the paired $t$-test. The obtained probability values, i.e., $p=0.544$ for $F m$ and $p=0.533$ for radiocarbon dates, corresponding to the calculated $t\left(t_{c}=0.650\right.$ for $F m$ and 0.689 for radiocarbon dates), are much greater than the requested significance level $(p=0.05)$. These values provide no evidence for rejecting the $\mathrm{H}_{0}$ (null) hypothesis.

Calibrated ages. Calibrated calendar (cal) ages are also shown in Table 1. The 1- $\sigma$ probability distribution was chosen to calculate calendar years. Each 1- $\sigma$ probability distribution corresponds to one or several ranges, out of which one (marked in bold) was 
selected as the most probable cal AD 1- $\sigma$ range of each sample. Calendar ages of samples represent the difference between $\mathrm{AD} 2008$ (year of dating) and the mean value of the selected 1- $\sigma$ range, with the corresponding error. Calendar ages of samples and errors were rounded to the nearest 5 years. For four samples $(1 a, 2 a, 2 b, 5 b)$, the $1-\sigma$ distribution corresponds only to one range. In the case of eight samples, for which there are two or three 1- $\sigma$ ranges, one range was selected for reasons discussed below. In six cases $(1 b, 3 a$, $3 b, 4 b, 5 a, 6 a)$, the probability of one range is significantly greater than the other(s); therefore, it was selected as cal $\mathrm{AD}$ range. Two samples $(4 a, 6 b)$ have two $1-\sigma$ ranges with almost equal probability distributions. In this case, the closest range to that selected for the corresponding twin sample $(4 b, 6 a)$ was chosen as cal $\mathrm{AD}$ range.

For calibration the general IntCal04 data set [14] was used rather than the SHCal04 data set for the Southern Hemisphere [17], as the latter does not yet contain information for lower southern latitudes and for Africa [6].

Age of Dorslandboom. The radiocarbon date of the oldest sample $3 b$ was of $993 \pm 20 \mathrm{BP}$, which corresponds to a calibrated age of $980 \pm 15$ years. The original large sample, out of which the small sample $3 b$ was extracted, originated from the collapsed double stem A, more precisely from the base of stem A1. Its dimensions were of 18 x $4 \mathrm{~cm}$ (length $\mathrm{x}$ width) and the restored curvature radius was $0.69 \mathrm{~m}$. Taking into account the diameter at breast height $(\mathrm{dbh})$ of stem A1, which was $2.70 \mathrm{~m}$, one can consider that this large sample and, consequently, the oldest dated sample $3 b$ originate practically from the midway between the center and the outside part/bark of stem A1. For determining the true age of stem A1, one should consider the literature data on the growth rate dynamics of African baobab and the severe growth decline of old trees $[18,6]$. The first radiocarbon investigation of an African baobab dated two samples collected from the center and from the midway between the center and the outside part adjacent to bark, respectively, of the 
stump of an old African baobab felled at Lake Kariba in 1960 [19]. The two radiocarbon dates were $1010 \pm 30$ and $740 \pm 30 \mathrm{BP}$ (the original paper reported errors of $\pm 100{ }^{14} \mathrm{C}$ years, due to certain arbitrary corrections). According to the present calibration curve IntCa104, these values correspond to $950 \pm 20$ (for the center) and $690 \pm 15$ years (for the midway between center and outside part). By adapting these values for stem A1 of Dorslandboom and considering the age of sample $3 \mathrm{~b}$, one obtains a theoretical age of 1350 \pm 15 years for the center of stem A1. Considering that Dorslandboom was older than the Lake Kariba tree and other possible errors, we estimate that the age of stem A1 and of the oldest part of Dorslandboom is of $1300 \pm 100$ years.

History of Dorslandboom's multi-stemmed trunk. Three twin samples (1-3) originate from stem A1, two samples $(4,5)$ from stem B and one (6) from stem E. The oldest twin samples $(3 a, 3 b)$ were collected from the deepest location, namely from the midway between the center and bark of stem A1. All other samples were collected from positions closer to the bark than to the center of the respective stem, namely A1, B or E.

Radiocarbon dates of the oldest twin samples originating from stem B $(5 a, 5 b)$ were $685 \pm 29$ and $717 \pm 25 \mathrm{BP}$, which correspond to calendar ages of $720 \pm 10$ and $730 \pm 10$ years. The original position of samples and the dimensions of bent stem B (which was almost fused with stem A1, before it toppled), indicate that the three largest stems of the trunk, i.e., A1, A2 and B, belong to the same old generation, with an age of 1200-1400 years (AD 600-800).

Radiocarbon dates of twin samples from the leaning stem E $(6 a, 6 b)$ were of only 255 \pm 29 and $218 \pm 28 \mathrm{BP}$, which correspond to calendar ages of $360 \pm 15$ and $350 \pm 10$ years. The positions of these samples along with the orientation of Dorslandboom's stems suggest that the five smaller stems, i.e., C, D, E, F and G, belong to a mature generation and have 
ages of 500-700 years (AD 1300-1500). They are very probably sprouts/shoots from fallen branches or from other possible collapsed stems which belonged to the old generation.

Observations made after 1880 indicate that the much smaller stems $\mathrm{X}$ and $\mathrm{Y}$, as well as the new shoots growing at the broken ends of toppled stems B, C and D, are less than 100 years old and belong to a young generation (after AD 1900).

These results evince that Dorslandboom is not only a multi-stemmed tree, but also a multi-generation baobab with knitted stems of different ages. According to the age of sample $3 b$, the mean annual increase in radius of stem A1 was only $0.704 \mathrm{~mm} \mathrm{yr}^{-1}$ over the past 980 years.

\section{Conclusions}

Wood samples collected from Dorslandboom were investigated by AMS radiocarbon dating. The statistical analysis shows no significant differences between fraction modern values and radiocarbon dates for samples analyzed with pretreatment and without pretreatment. The results demonstrate that direct combustion of tropical wood samples with low non-structural mobile carbon content, by laser ablation followed by continuousflow analysis in an AMS gas ion source can produce accurate dating information. The results indicate that such wood samples can also be accurately radiocarbon dated even without pretreatment, by standard AMS or more traditional techniques.

\section{Acknowledgements}

We would like to thank Dr. Paul Zador, Andries H. Alberts, Magriet van der Nest, Dr. Eugene Gergely, Dan Rus-Staroste, Codruta and Grigore Bojescu for help and useful discussions. This material is based on work supported by U.S. National Science Foundation under Cooperative Agreement OCE-022828996. Part of the research was supported by grants from the Romanian Academy and the Romanian National University Research Council (PN II - ID 2354) and also by Nova Research Inc. 


\section{References}

[1] M. Worbes, Dendrochronologia 20 (2002) 217-231.

[2] C. Coster, Ann. Jard. Bot. Bruitenzorg 37 (1927) 49-160.

[3] M. Worbes, J. Ecol. 87 (1999) 391-403.

[4] E. Fichtler, D.A. Clark, M. Worbes, Biotropica 35 (2003) 306-317.

[5] M. Worbes, IAWA J. 16 (1995) 337-351.

[6] A. Patrut, K.F. von Reden, D.A. Lowy, A.H. Alberts, J.W. Pohlman, R. Wittmann, D.

Gerlach, L. Xu, C.S. Mitchell, Tree Physiol. 27 (2007) 1569-1574.

[7] J.B. Gaudinski, T.E. Dawson, S. Quideau, E.A. Schuur, J.S. Roden, S.E. Trubmore, D.R. Sandquist, S-W. Oh, R.E. Wasylishen, Anal. Chem. 77 (2005) 7212-7224.

[8] K.F. von Reden et al., Nucl. Instr. and Meth. B 223-224 (2004) 50-54.

[9] B.X. Han, K.F. von Reden, M.L. Roberts, R.J. Schneider, J.M. Hayes, W.J. Jenkins, Nucl. Instr. and Meth. B 259 (2007) 111-117.

[10] S.M. Chapotin, J.H. Razanameharikaza, N.M. Holbrook, Am. J. Bot. 93 (2006) 12511264.

[11] T. Pakenham, In search of remarkable trees: On Safari in Southern Africa, Orion, London, 2007, pp. 31-33.

[12] I.U. Olsson, Radiometric Methods, in B. Berglund (Ed.), Handbook of Holocene palaeoecolgy and palaeohydrology, Wiley, Chichester, 1986, pp. 273-312.

[13] C. Bronk Ramsey, OxCal Program, v4.0.3, http://www.rlaha.ox.ac.uk/oxcal/ oxcal.html, 2008.

[14] P.J. Reimer et al., Radiocarbon 46 (2004) 1029-1058.

[15] R.R. Sokal, F.J. Rohlf, Biometry: The principles and practice of statistics in biological research. 3rd edition. W.H. Freeman, New York, 1995, pp. 698-703.

[16] -, Statistica 7.0, http://www.statsoft.com, 2008. 
[17] F.G. McCormack, A.G. Hogg, P.G. Blackwell, C.E. Buck, T.F.G. Higham, P.J. Reimer, Radiocarbon 46 (2004) 1087-1092.

[18] F. von Breitenbach, J. Dendrology 5 (1985) 1-21.

[19] E.R. Swart, Nature 198 (1963) 708-709. 


\section{Figure captions}

Fig. 1. Top view of Dorslandboom's multi-generation trunk, showing its knitted stems; stem labels: A-G and X, Y. The arrows indicate the approximate position of samples. (C) Thomas Pakenham

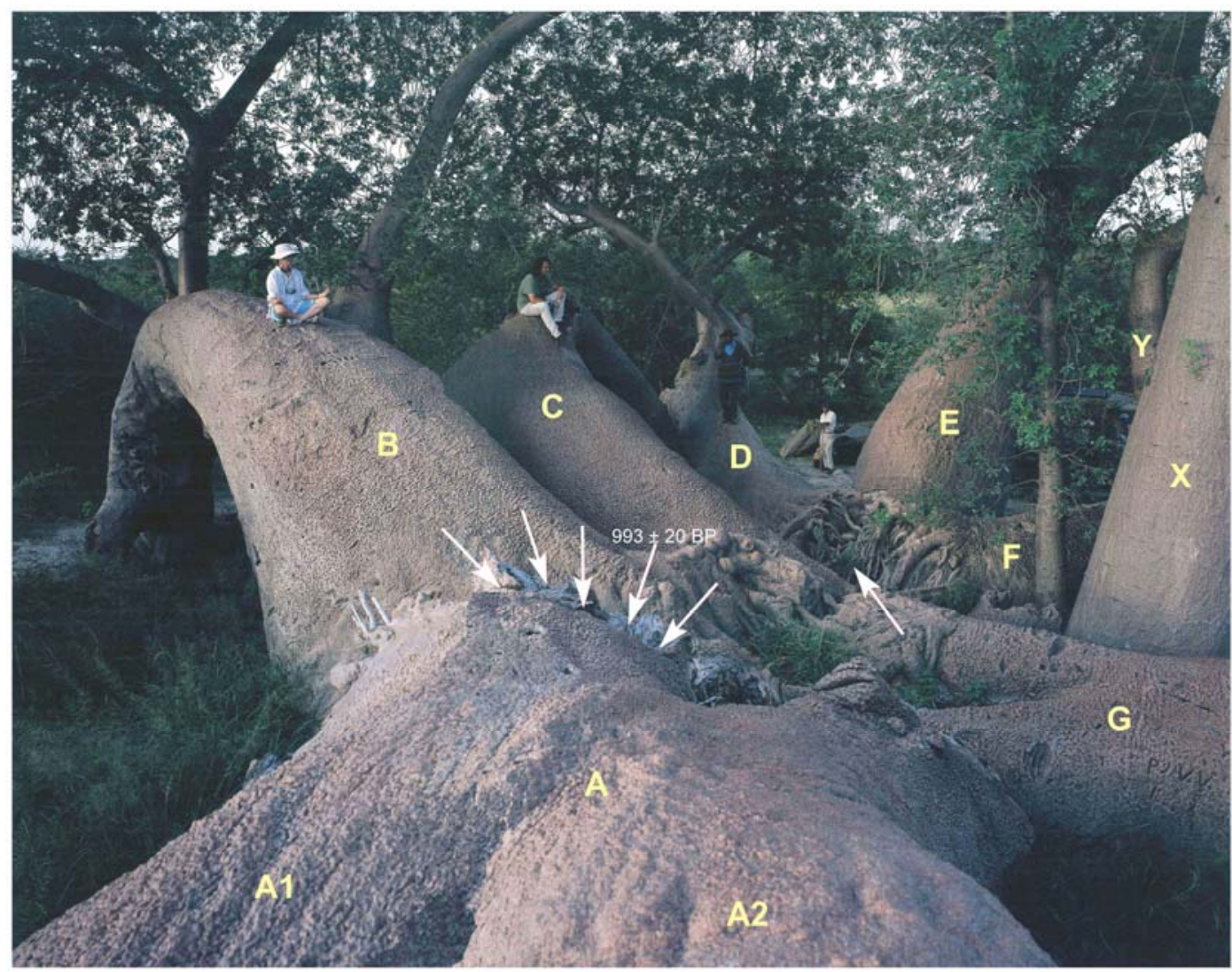


Table 1. AMS radiocarbon dating results and calibration to calendar ages.

\begin{tabular}{|c|c|c|c|c|}
\hline $\begin{array}{l}\text { Sample } \\
\text { code } \\
\text { (Stem) }\end{array}$ & $\begin{array}{l}\text { Fraction modern } \\
\text { [error] }\end{array}$ & $\begin{array}{c}\text { Radiocarbon date } \\
\text { [error] } \\
\left({ }^{14} \mathrm{C} \text { yr BP }\right)\end{array}$ & $\begin{array}{c}\text { Cal AD age } \\
1-\sigma \text { range(s) } \\
\text { (cal yr AD) } \\
\text { [relative area] }\end{array}$ & $\begin{array}{c}\text { Age of sample } \\
\text { [error] } \\
\text { (cal yr) }\end{array}$ \\
\hline $1 a(\mathrm{~A} 1)$ & $\begin{array}{c}0.9383 \\
{[ \pm 0.0032]}\end{array}$ & $512[ \pm 26]$ & $1410-1434[68.2 \%]$ & $585[ \pm 10]$ \\
\hline $1 b(\mathrm{~A} 1)$ & $\begin{array}{c}0.9314 \\
{[ \pm 0.0034]}\end{array}$ & $571[ \pm 27]$ & $\begin{array}{l}\mathbf{1 3 2 0 - 1 3 5 0}[\mathbf{4 1 . 1 \% ]} \\
1391-1411[27.1 \%]\end{array}$ & $675[ \pm 15]$ \\
\hline $2 a(\mathrm{~A} 1)$ & $\begin{array}{c}0.8978 \\
{[ \pm 0.0031]}\end{array}$ & $866[ \pm 25]$ & $1160-1215[68.2 \%]$ & $820[ \pm 25]$ \\
\hline $2 b(\mathrm{~A} 1)$ & $\begin{array}{c}0.9029 \\
{[ \pm 0.0033]}\end{array}$ & $821[ \pm 27]$ & $1208-1260[68.2 \%]$ & $775[ \pm 25]$ \\
\hline $3 a(\mathrm{~A} 1)$ & $\begin{array}{c}0.8899 \\
{[ \pm 0.0035]}\end{array}$ & $937[ \pm 28]$ & $\begin{array}{l}1036-1054[13.1 \%] \\
\mathbf{1 0 7 9 - 1 1 5 3}[55.1 \%]\end{array}$ & $890[ \pm 35]$ \\
\hline $3 b(\mathrm{~A} 1)$ & $\begin{array}{c}0.8837 \\
{[ \pm 0.0025]}\end{array}$ & $993[ \pm 20]$ & $\begin{array}{c}999-1002[1.6 \%] \\
\mathbf{1 0 1 3 - 1 0 4 2}[\mathbf{5 8 . 2 \%}] \\
1107-1118[8.4 \%]\end{array}$ & $980[ \pm 15]$ \\
\hline $4 a(\mathrm{~B})$ & $\begin{array}{c}0.9321 \\
{[ \pm 0.0025]}\end{array}$ & $565[ \pm 20]$ & $\begin{array}{l}\mathbf{1 3 2 5}-1344[34.4 \%] \\
1394-1411[33.8 \%]\end{array}$ & $675[ \pm 10]$ \\
\hline $4 b(\mathrm{~B})$ & $\begin{array}{c}0.9310 \\
{[ \pm 0.0036]}\end{array}$ & $574[ \pm 29]$ & $\begin{array}{l}\mathbf{1 3 1 8 - 1 3 5 2}[\mathbf{4 3 . 4 \%}] \\
1390-1410[24.8 \%]\end{array}$ & $675[ \pm 15]$ \\
\hline $5 a(\mathrm{~B})$ & $\begin{array}{c}0.9183 \\
{[ \pm 0.0036]}\end{array}$ & $685[ \pm 29]$ & $\begin{array}{l}\text { 1277-1301 [48.3\%] } \\
1368-1382[19.9 \%]\end{array}$ & $720[ \pm 10]$ \\
\hline $5 b(\mathrm{~B})$ & $\begin{array}{c}0.9146 \\
{[ \pm 0.0031]}\end{array}$ & $717[ \pm 25]$ & $1268-1290[68.2 \%]$ & $730[ \pm 10]$ \\
\hline $6 a(\mathrm{~F})$ & $\begin{array}{c}0.9687 \\
{[ \pm 0.0036]}\end{array}$ & $255[ \pm 29]$ & $\begin{array}{l}1532-1537[3.0 \%] \\
\mathbf{1 6 3 5 - 1 6 6 7}[\mathbf{5 1 . 2 \%}] \\
1783-1797[14.0 \%]\end{array}$ & $360[ \pm 15]$ \\
\hline $6 b(\mathrm{~F})$ & $\begin{array}{c}0.9732 \\
{[ \pm 0.0035]}\end{array}$ & $218[ \pm 28]$ & $\begin{array}{l}\mathbf{1 6 4 8 - 1 6 7 3}[\mathbf{2 8 . 9 \%}] \\
1778-1799[28.3 \%] \\
1942-1953[11.0 \%]\end{array}$ & $350[ \pm 10]$ \\
\hline
\end{tabular}

